\title{
The nail points to the diagnosis
}

\section{Stephanie YK Tong, HM Luk *, Tony MF Tong, Ivan FM Lo}

Hong Kong Med J 2015;21:573.e3-5 DOI: 10.12809/hkmj154728

A 54-year-old man was referred to the genetic clinic with familial nail dysplasia in September 2012 (Fig 1). On further questioning, he reported recurrent knee pain due to patellar dislocation. There was no elbow involvement or renal problem. A skeletal survey was performed in view of his skeletal complaint (Fig 2). His family history was significant: his paternal grandfather, father, and two of his paternal uncles also had nail dysplasia and knee problems, but had undergone no formal medical assessment. What is the diagnosis?

\section{What is his diagnosis?}

The combination of nail dysplasia, patella hypoplasia, The diagnosis of NPS is usually based on clinical and iliac horn led to the clinical diagnosis of findings. It is straightforward when the classic tetrad

nail-patella syndrome (NPS). This syndrome is of abnormal nails, elbows, knees, and iliac horns also known as Fong disease or hereditary osteoonychodysplasia. Multiple organ systems are affected including the nails, the eyes, the kidneys, and the skeleton. The clinical presentation of NPS can be highly heterogeneous and is summarised in the Table. ${ }^{1,2}$ It is a rare autosomal dominant disease with a prevalence of about 1 in 50000 newborn. ${ }^{1}$ It is highly penetrant but with significant intra- and interfamilial variability in expression.

\section{Is there any genetic testing available for} such condition and what is the underlying pathogenesis?
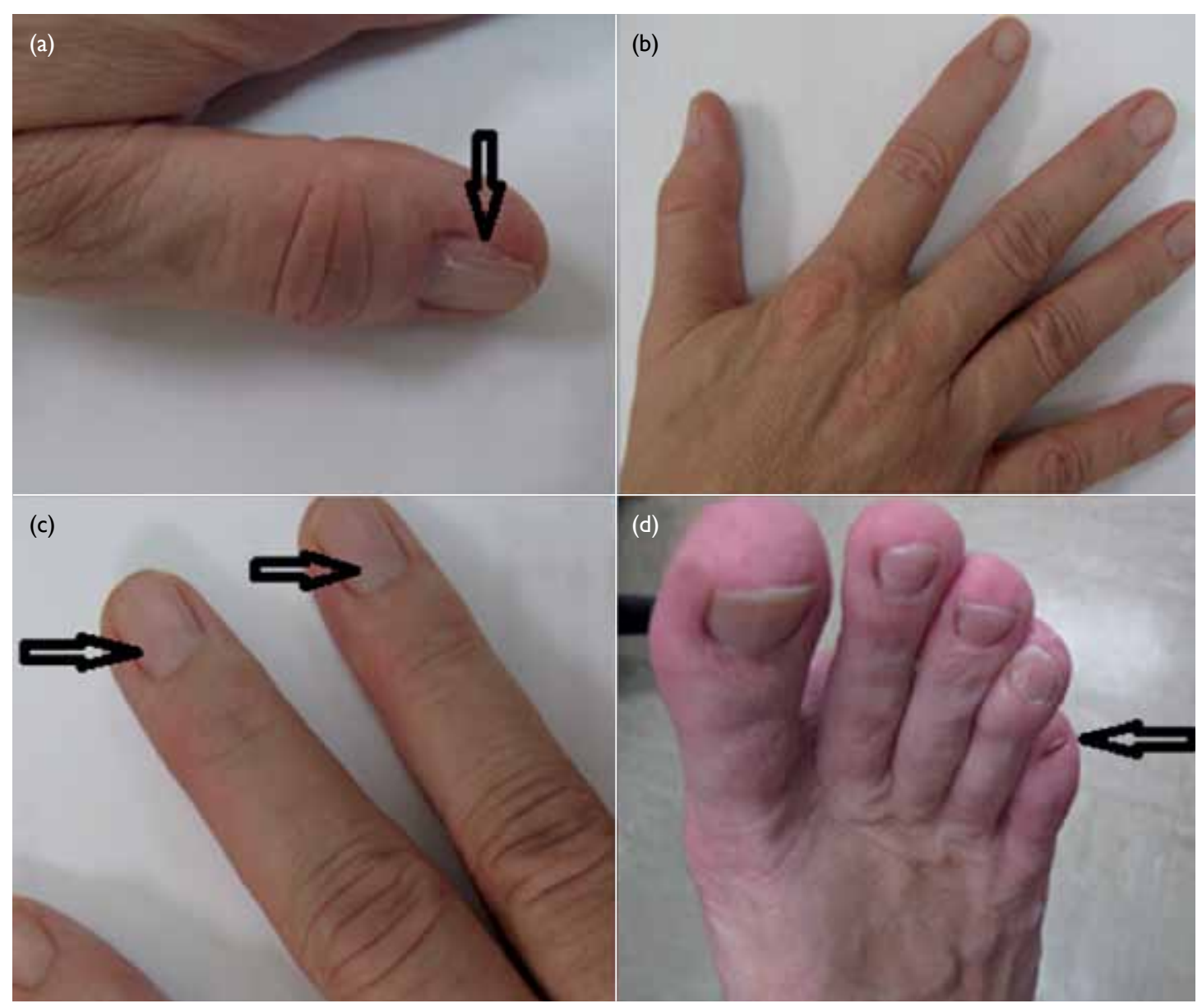

FIG I. (a) The left thumbnail is dysplastic with longitudinal splitting. The ulnar side is more severely affected (arrow). (b) The skin creases on the dorsal aspect of the distal interphalangeal joints are absent. (c) Triangular lunulae are evident on all fingernails (arrows). (d) The little toenail is also hypoplastic (arrow) 

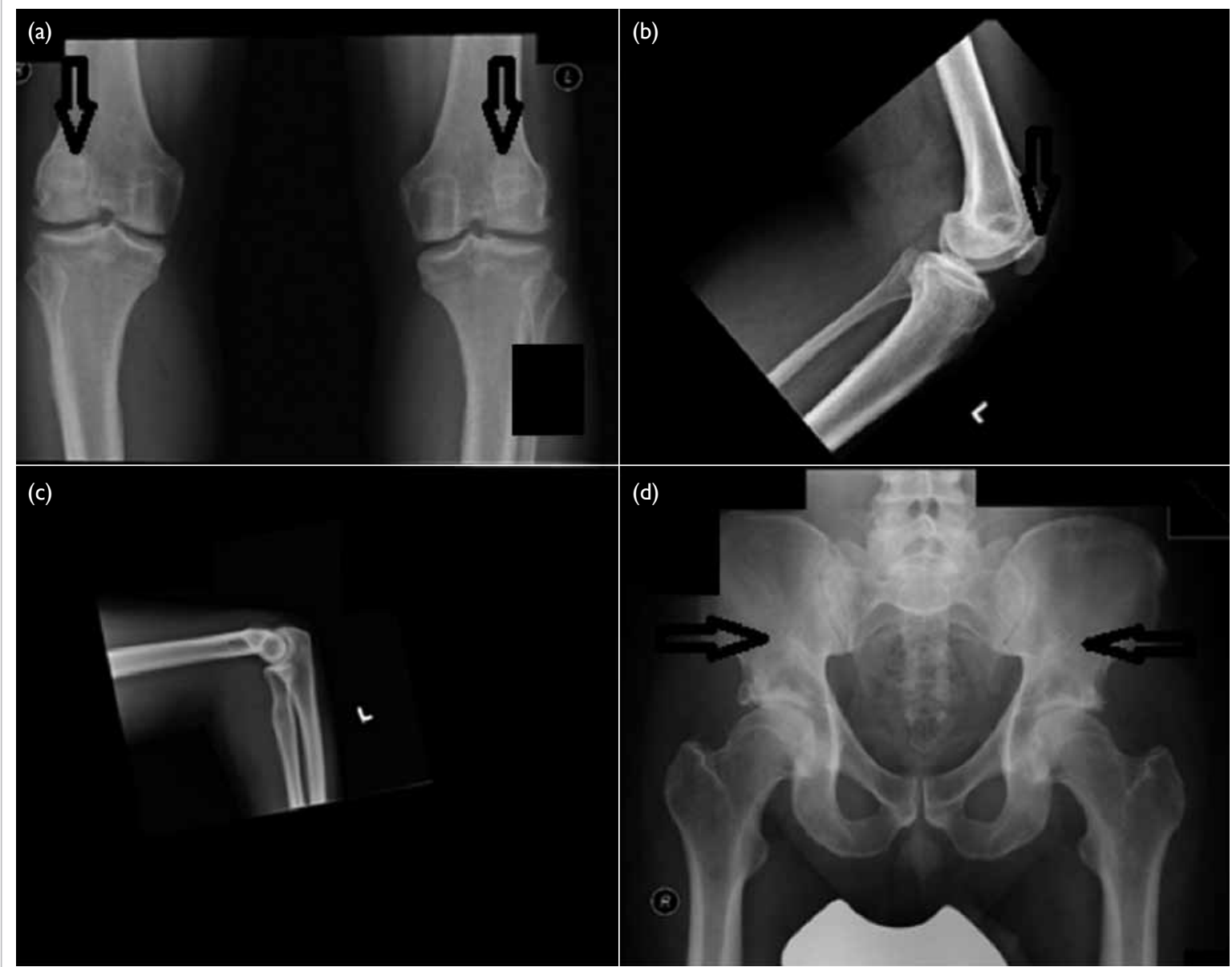

FIG 2. ( $a$ and b) The patellae are hypoplastic and laterally displaced (arrows). (c) A radiograph of the elbow showing no abnormalities. (d) Bilateral iliac horns on the posterolateral aspect of the pelvis are observed (arrows)

TABLE. Clinical manifestations of nail-patella syndrome ${ }^{1,2}$

\begin{tabular}{|c|c|c|}
\hline Organ involvement & Clinical features & Prevalence \\
\hline Nail & $\begin{array}{l}\text { Nail dysplasia } \\
\text { Triangular nail lunulae } \\
\text { Nail hypoplasia } \\
\text { Longitudinal ridging } \\
\text { Anonychia, hemianonychia } \\
\text { Splitting spoon-shaped nail } \\
\text { Flaky nail }\end{array}$ & $93 \%$ \\
\hline \multirow[t]{4}{*}{ Skeletal } & $\begin{array}{l}\text { Knee dysplasia } \\
\text { Patella aplasia/hypoplasia } \\
\text { Hypoplasia of lateral femoral condyle }\end{array}$ & $93 \%$ \\
\hline & $\begin{array}{l}\text { Elbow dysplasia } \\
\text { Radial head hypoplasia } \\
\text { Capitellum hypoplasia }\end{array}$ & $93 \%$ \\
\hline & $\begin{array}{l}\text { Pelvic dysplasia } \\
\text { Iliac horns }\end{array}$ & $70-80 \%$ \\
\hline & $\begin{array}{l}\text { Foot dysplasia } \\
\text { Equinovarus, equinovalgus }\end{array}$ & \\
\hline Ophthalmological & $\begin{array}{l}\text { Primary open-angle glaucoma } \\
\text { Ocular hypertension } \\
\text { Lester's sign of iris }\end{array}$ & $\begin{array}{c}10 \% \\
7 \% \\
42-54 \%\end{array}$ \\
\hline Renal & $\begin{array}{l}\text { Proteinuria }+/ \text { - haematuria } \\
\text { Renal failure }\end{array}$ & $\begin{array}{c}12-55 \% \\
5-14 \%\end{array}$ \\
\hline
\end{tabular}

are present. Nonetheless molecular genetic testing should be considered when the diagnosis is in doubt, or when prenatal or pre-implantation diagnosis is desired. The $L M X 1 B$ gene is the only gene known to be associated with NPS. Sequence analysis would identify the $L M X 1 B$ gene mutation in $85 \%$ of cases of NPS.

$L M X 1 B$ gene sequencing was performed for this patient (Fig 3) and revealed a missense mutation LMX1B NM_002316.3\}:c.[175T >C];[=];LMX1B\{NP _002307.2\}:p.[Cys59Arg];[=]. This changed the 59th amino acid from cysteine to arginine in the LIM-A domain of the LMX1B protein. It was located in an evolutionarily highly conserved region and has been reported in the literature to be associated with NPS. Therefore, it was considered to be pathogenic. ${ }^{3}$

To date, more than 150 mutations of the $L M X 1 B$ gene have been reported, but no clear genotypephenotype correlation has been demonstrated. $L M X 1 B$ has been demonstrated in animal models to be involved in multiple developmental functions including dorso-ventral patterning of the limb 


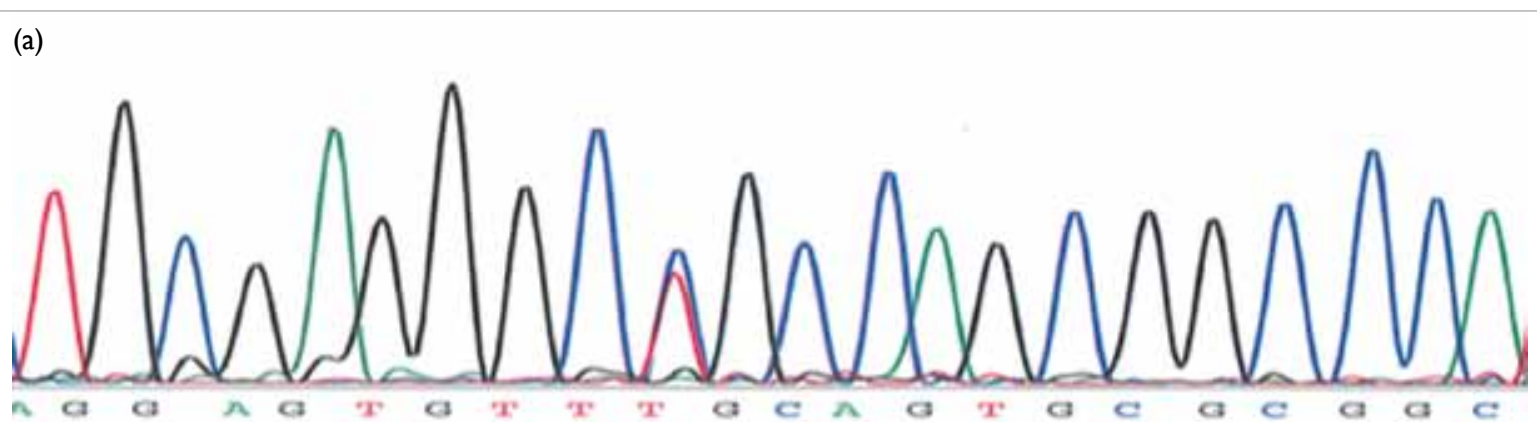

(b)

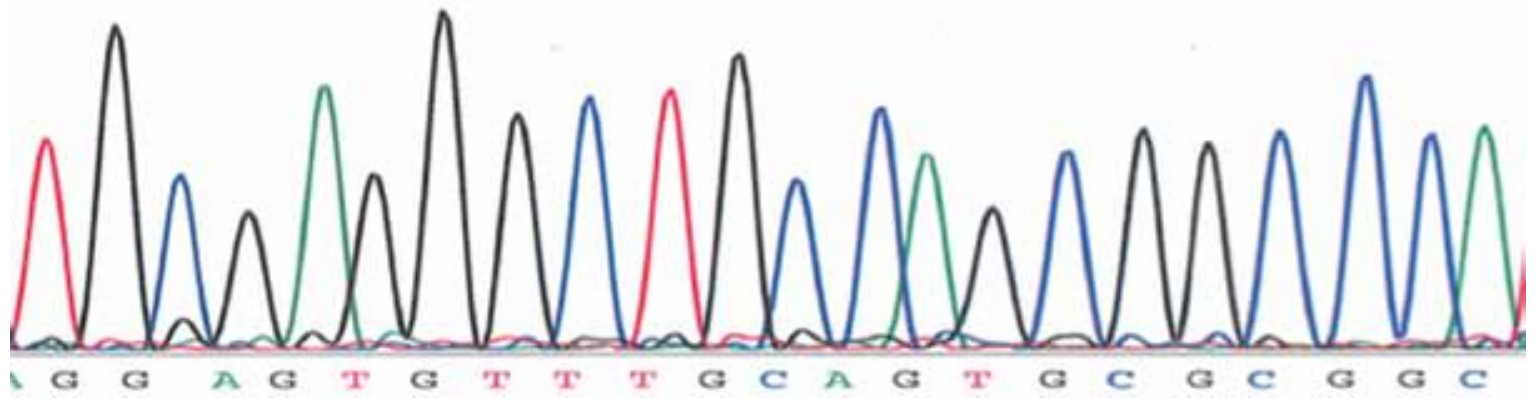

FIG 3. DNA sequence chromatographs of the patient. (a) A heterozygous c. I75T>C mutation in exon 2 of $L M X I B$ gene, and (b) wild-type sequence for comparison

BOX. Recommended management for patients with nail-patella syndrome ${ }^{2}$

- Annual screening for renal disease from birth that includes urinalysis and blood pressure measurement. Referral to renal physician if abnormality is detected.

- Screening for intra-ocular pressure every 2 years from adulthood.

- Magnetic resonance imaging should be considered for abnormal anatomy of both bone and soft tissue if clinically indicated.

- Genetic counselling should be offered to all patients with nail-patella syndrome.

bud, and cellular differentiation in the kidney. Nonetheless the exact pathogenesis of NPS has not been elucidated. ${ }^{4}$

\section{How to manage this patient?}

Upon initial diagnosis, comprehensive renal, orthopaedic, and ophthalmological assessments are essential. The renal manifestation strongly affects the long-term prognosis. Kidney involvement occurs in $30 \%$ to $50 \%$ of patients, but kidney failure only occurs in $3 \%$ to $5 \% .^{2}$ Since nephropathy may not develop until later in life, prospective monitoring is essential for all NPS patients. Primary open-angle glaucoma or ocular hypertension occurs in $10 \%$ of NPS patients so regular eye surveillance is also warranted. Nailpatella syndrome is an autosomal dominant disorder with a $50 \%$ chance of occurrence in offspring, thus genetic counselling is essential $\left(\mathrm{Box}^{2}\right)$. Genetic testing of other at-risk family members, and prenatal and pre-implantation genetic diagnoses are possible only if the disease-causing mutation is known in the index patient.
SYK Tong, BSc

HM Luk *, FHKAM (Paediatrics)

TMF Tong, MSo

IFM LO, FHKAM (Paediatrics)

Clinical Genetic Service, Department of Health, Hong Kong

* Corresponding author: luksite@gmail.com

\section{References}

1. Bongers EM, Gubler MC, Knoers NV. Nail-patella syndrome. Overview on clinical and molecular findings. Pediatr Nephrol 2002;17:703-12.

2. Sweeney E, Fryer A, Mountford R, Green A, McIntosh I. Nail-patella syndrome: a review of the phenotype aided by developmental biology. J Med Genet 2003;40:153-62.

3. Clough MV, Hamlington JD, McIntosh I. Restricted distribution of loss-of-function mutations within the $L M X 1 B$ genes of nail-patella syndrome patients. Hum Mutat 1999;14:459-65.

4. Chen $\mathrm{H}$, Lun $\mathrm{Y}$, Ovchinnikov D, et al. Limb and kidney defects in $L M X 1 B$ mutant mice suggest an involvement of $L M X 1 B$ in human nail patella syndrome. Nat Genet 1998;19:51-5. 